\title{
A Practical Split-Window Algorithm for Estimating Land Surface Temperature from Landsat 8 Data
}

\section{Chen Du ${ }^{1}$, Huazhong Ren ${ }^{1}$, Qiming Qin ${ }^{1, *}$ Jinjie Meng ${ }^{1}$ and Shaohua Zhao ${ }^{2}$}

1 Institute of Remote Sensing and Geographic Information System, Peking University, Beijing 100871, China; E-Mails: du-ch@163.com (C.D.); renhuazhong@pku.edu.cn (H.R.); mengjinjie186pku@163.com (J.M.)

2 Satellite Environmental Application Center, Ministry of Environmental Protection, Beijing 100094, China; E-Mail: zshyytt@126.com (S.Z.)

* Author to whom correspondence should be addressed; E-Mail: qmqinpku@163.com; Tel.: +86-10-6276-4430.

Academic Editors: Zhao-Liang Li, Jose A. Sobrino, Xiaoning Song and Prasad S. Thenkabail Received: 17 October 2014 / Accepted: 4 January 2015 / Published: 8 January 2015

\begin{abstract}
This paper developed a practical split-window (SW) algorithm to estimate land surface temperature (LST) from Thermal Infrared Sensor (TIRS) aboard Landsat 8. The coefficients of the SW algorithm were determined based on atmospheric water vapor sub-ranges, which were obtained through a modified split-window covariance-variance ratio method. The channel emissivities were acquired from newly released global land cover products at $30 \mathrm{~m}$ and from a fraction of the vegetation cover calculated from visible and near-infrared images aboard Landsat 8. Simulation results showed that the new algorithm can obtain LST with an accuracy of better than $1.0 \mathrm{~K}$. The model consistency to the noise of the brightness temperature, emissivity and water vapor was conducted, which indicated the robustness of the new algorithm in LST retrieval. Furthermore, based on comparisons, the new algorithm performed better than the existing algorithms in retrieving LST from TIRS data. Finally, the SW algorithm was proven to be reliable through application in different regions. To further confirm the credibility of the SW algorithm, the LST will be validated in the future.
\end{abstract}

Keywords: Land Surface Temperature (LST); Landsat 8; split-window algorithm; Thermal Infrared (TIR) 


\section{Introduction}

Land surface temperature (LST) is a key parameter in the physics of land-surface processes regionally and globally; LST has been used in soil moisture estimation [1] and in climatic, hydrological, ecological and biogeochemical studies. Currently, LST can only be obtained over large spatial and temporal scales through remote sensing data, which have attracted much attention in the last three decades [2,3]. Consequently, many LST retrieval methods have been proposed from remotely sensed data, particularly multi-channel thermal infrared (TIR) data, and these methods can be roughly grouped into three categories: the single-channel algorithm, multi-channel methods (e.g., the split-window algorithm [4-6] and the temperature and emissivity separation method [7]) and multi-time methods (e.g., the temperature-independent spectral indices method [8], two-temperature method $[9,10]$ and the physical day and night algorithm [11]). Some algorithms, such as the iterative spectrally smooth temperature-emissivity separation [12] and the alpha-driven emissivity method [13], have also been proposed to retrieve both LST and emissivity from hyperspectral TIR data. Amongst these methods, the split-window algorithm is the most commonly used, given that this algorithm removes the atmospheric effect and obtains the LST from the linear or nonlinear combination of the brightness temperatures of two adjacent channels centered at 11 and $12 \mu \mathrm{m}$.

Landsat 8, also previously called Landsat Date Continuity Mission, extends the remarkable 40-year Landsat record and has enhanced capabilities, including new spectral bands in visible and thermal infrared wavelengths, an improved sensor for signal-to-noise performance and associated improvements in radiometric resolution, and an improved duty cycle to collect significantly more images daily [14]. The Thermal Infrared Sensor (TIRS) instrument is one of the major payloads aboard this satellite which can observe the land surface by using the split-window thermal infrared channels (CH10: $10.6 \mu \mathrm{m}$ to $11.2 \mu \mathrm{m}$; CH11: $11.5 \mu \mathrm{m}$ to $12.5 \mu \mathrm{m}$ ) at a resolution of $100 \mathrm{~m}$. Compared with the TIRS predecessors, namely, the Thematic Mapper (TM) and the Enhanced Thematic Mapper Plus (ETM+), which only have one thermal infrared channel, the TIRS instrument possesses two advantages. First, the TIRS has two thermal infrared channels in the atmospheric window that provide a new LST retrieval opportunity using the widely used split-window algorithm rather than the single-channel method. Second, as shown in Figure 1, the spectral filters of TIRS two bands present narrower bandwidth than that of the thermal band onboard TM and $\mathrm{ETM}+$, the two thermal infrared channels have narrower bandwidths in the TIRS, which can capture finer land surface information, as shown in Figure 1 [15-17]. Consequently, the LST retrieval algorithm improves our understanding of the new sensor (TIRS) especially on response characteristics to land surface energy, and this algorithm will provide a valuable reference for future studies on the potential capability in terms of LST measurement.

This study aims to develop an operational split-window algorithm (SW) for LST estimation using two thermal infrared channels (TIRS 10: $10.60 \mu \mathrm{m}$ to $11.19 \mu \mathrm{m}$; and TIRS $11: 11.50 \mu \mathrm{m}$ to $12.51 \mu \mathrm{m}$ ) of the TIRS images. This paper is organized as follows: Section 2 describes the principle associated with LST retrieval through the SW algorithm, and this section also presents the algorithm development for the TIRS data. Section 3 shows the SW algorithm coefficients and the ways to obtain land surface emissivity and atmospheric water vapor. Section 4 illustrates the conducted model sensitivity and consistency using several key parameters, such as brightness temperature noise, land surface emissivity (LSE) and water 
vapor. Section 5 focuses on the application of the SW algorithm in TIRS images for LST product estimations. Section 6 presents the conclusion.

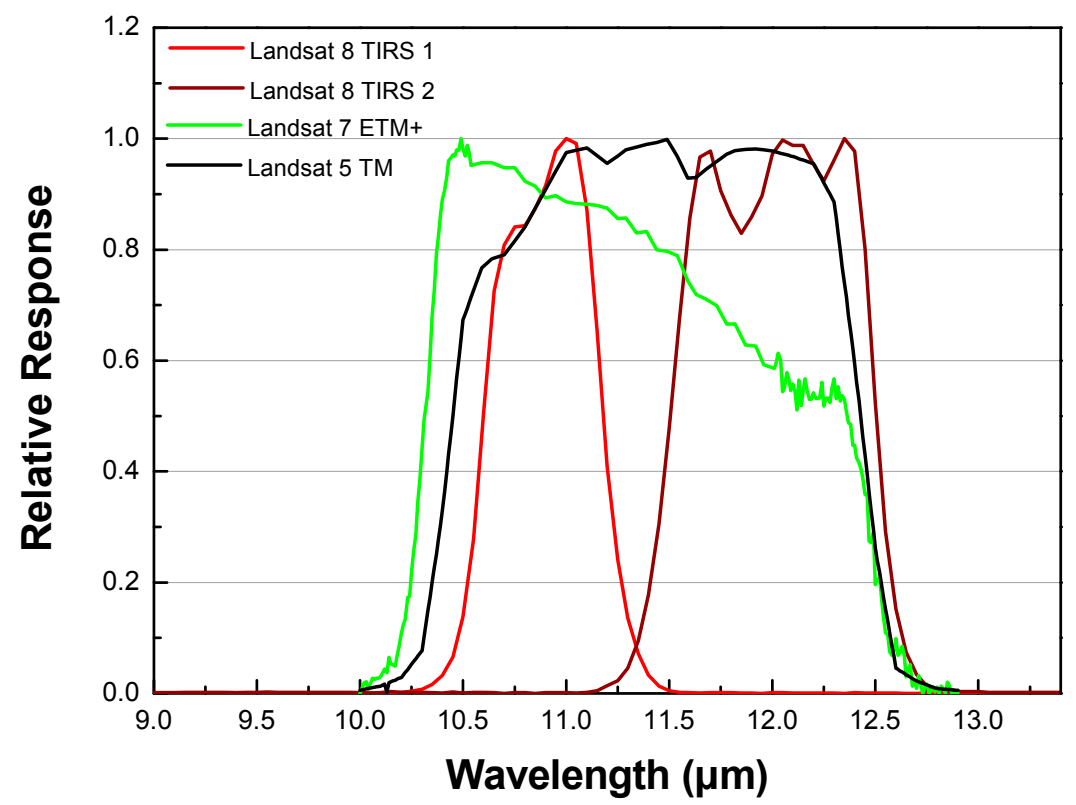

Figure 1. Spectral response functions of the thermal bands of the different sensors on board the Landsat platforms.

\section{Methodology}

\subsection{Split-Window Algorithm Principle}

Based on radiative transfer theory, for a cloud-free atmosphere under thermodynamic equilibrium, the channel radiance $B_{i}\left(T_{i}\right)$ measured on top of the atmosphere (TOA) in a thermal infrared channel of the sensor aboard the satellite is provided with a significant approximation as follows $[16,18]$ :

$$
B_{i}\left(T_{i}\right)=\varepsilon_{i} B_{i}\left(T_{s}\right) \tau_{i}+\left(1-\varepsilon_{i}\right) R_{a t m_{-} i}^{\downarrow} \tau_{i}+R_{a t m_{-} i}^{\uparrow}
$$

where $\tau_{i}$ is the effective transmittance of the atmosphere in channel $i$, and $\varepsilon_{i}$ is the channel effective surface emissivity. $B_{i}$ is the Planck function, and $B_{i}\left(T_{s}\right)$ is the measured radiance if the surface is a black body with a surface temperature $T_{s}(\mathrm{~K}), R_{\text {atm } \_}^{\uparrow}$ and $R_{\text {atm } \_}^{\downarrow} i$ are the upward and downward atmospheric thermal radiance. The first term on the right side of Equation (1) represents the surface emission attenuated by the atmosphere. The second term represents the downward atmospheric thermal radiance reflected by the surface and which reaches the sensor. The third term represents the upward atmospheric emission towards the sensor. From Equation (1), we can deduce that LST retrieval requires knowledge of surface emissivity and atmospheric information.

The split-window algorithm removes the atmospheric effect through differential atmospheric absorption in the two adjacent thermal infrared channels centered at about 11 and $12 \mu \mathrm{m}$, and the linear or nonlinear combination of the brightness temperatures is finally applied for LST estimation. Given that this algorithm does not require accurate information about the atmospheric profiles during satellite acquisition, such algorithms have been widely used in LST retrieval from several sensors. A new refinement of the generalized split-window algorithm proposed by Wan (2014) [19] is added with a quadratic term of the 
difference amongst the brightness temperatures $\left(T_{i}, T_{j}\right)$ of the adjacent thermal infrared channels, which can be expressed as

$$
L S T=b_{0}+\left(b_{1}+b_{2} \frac{1-\varepsilon}{\varepsilon}+b_{3} \frac{\Delta \varepsilon}{\varepsilon^{2}}\right) \frac{T_{i}+T_{j}}{2}+\left(b_{4}+b_{5} \frac{1-\varepsilon}{\varepsilon}+b_{6} \frac{\Delta \varepsilon}{\varepsilon^{2}}\right) \frac{T_{i}-T_{j}}{2}+b_{7}\left(T_{i}-T_{j}\right)^{2}
$$

where $T_{i}$ and $T_{j}$ are the TOA brightness temperatures measured in channels $i(\sim 11.0 \mu \mathrm{m})$ and $j$ $(\sim 12.0 \mu \mathrm{m})$, respectively; $\varepsilon$ is the average emissivity of the two channels (i.e., $\left.\varepsilon=0.5\left[\varepsilon_{i}+\varepsilon j\right]\right)$, whilst $\Delta \varepsilon$ is the channel emissivity difference (i.e., $\left.\Delta \varepsilon=\varepsilon_{i}-\varepsilon_{j}\right) ; b_{k}(\mathrm{k}=0,1, \ldots 7)$ are the algorithm coefficients derived in the following simulated dataset.

\subsection{Algorithm Development for Landsat 8}

Given the unavailability of a database of in situ LST measurements that coincide with the Landsat 8 overpass, the coefficients $b_{\mathrm{k}}$ in Equation (2) are obtained through numerical simulation with different atmospheric and surface conditions.

In our simulation, Thermodynamic Initial Guess Retrieval (TIGR) atmospheric profiles are considered. The TIGR database is constructed by the Laboratoire de Meteorologie Dynamique, and TIGR represents a worldwide set of atmospheric situations (2311 radio soundings) from polar to tropical atmospheres with a column water vapor of $0.1 \mathrm{~g} / \mathrm{cm}^{2}$ to $8 \mathrm{~g} / \mathrm{cm}^{2}$ [20,21]. In one of the levels, the profiles with a relative humidity greater than $90 \%$ are discarded as under a cloudy condition, which results in a total of 946 atmospheric situations under clear skies with water vapor ranging from $0.06 \mathrm{~g} / \mathrm{cm}^{2}$ to $6.3 \mathrm{~g} / \mathrm{cm}^{2}$. According to these profiles, the MODTRAN 5.2 atmospheric transmittance/radiance code is used to calculate the channel atmospheric parameters $\left(\tau_{i}, R_{a t m_{-} i}^{\uparrow}\right.$ and $\left.R_{a t m_{-} i}^{\downarrow}\right)$ in Equation (1) of each atmospheric profile with a spectral integration of the response filters of the two TIRS channels.

For the surface conditions, the LST in the simulation are designed with 7 levels according to the bottom atmospheric temperature $T_{0}$ of each atmospheric profile, that is, the LST range from $T_{0}-10 \mathrm{~K}$ to $T_{0}+20 \mathrm{~K}$ in a $5 \mathrm{~K}$ step. In addition, a total of 53 emissivity spectra in $3 \mu \mathrm{m}$ to $14 \mu \mathrm{m}$ are selected from the American Advanced Spaceborne Thermal Emission Reflection (ASTER) emissivity database [22], including 5 water types, 8 man-made target types, 4 vegetation types, 5 rock types, 30 soil types and 1 mineral type. Notably, by contrast to other studies [23,24], man-made targets are considered in this study because the LST products from TIRS are used in urban environmental studies, given the advantages of these products in terms of the finer resolution compared with the Moderate-resolution Imaging Spectroradiometer (MODIS) and Advanced Very High Resolution Radiometer (AVHRR) products, and also the free charge compared with the ASTER product with a resolution of $90 \mathrm{~m}$.

Finally, combined with the atmospheric parameters $\left(\tau_{i}, R_{a t m_{-} i}^{\uparrow}\right.$ and $\left.R_{a t m_{-} i}^{\downarrow}\right)$, LST and emissivity, the channel radiance at the TOA is determined according to Equation (1), and the brightness temperatures $T_{i}$ and $T_{j}$ are obtained from the inverse of Planck's law in the two channels. Given that the field of view (FOV) of the TIRS is about 15 degrees and almost observes the land surface at a nadir direction, meanwhile, the angular effect of atmospheric data, land surface emissivity, and LST as reported in our previous study is also not remarkable $[25,26]$ in FOV $=15$ degrees, it is reasonable to ignore the angular variation in the development of SW algorithm. Thus, a total of 350,966 different groups of $T_{i}$ and $T_{j}$, LST, and $\varepsilon$ and $\Delta \varepsilon$ are obtained (946 atmospheres $\times 53$ emissivity $\times 7$ surface temperatures). Thus, the coefficients $b_{0}-b_{7}$ in Equation (2) can be determined through a statistical regression method. 


\section{Algorithm Results}

\subsection{Algorithm Coefficients}

Given that the radiation in the thermal infrared wavelength was attenuated by the atmospheric column water vapor (CWV), we calculated the coefficients $b_{0}-b_{7}$ in Equation (2) independently on the CWV to improve the LST retrieval accuracy. Thus, in our SW algorithm, the CWV was divided into 5 sub-ranges and an overlap of $0.5 \mathrm{~g} / \mathrm{cm}^{2}$ was considered between 2 adjacent sub-ranges, which resulted in [0.0, 2.5], $[2.0,3.5],[3.0,4.5],[4.0,5.5]$ and $[5.0,6.3] \mathrm{g} / \mathrm{cm}^{2}$. The CWV was retrieved from a modified split-window covariance and variance ratio method, as stated in Section 3.3. However, given the somewhat unsuccessful CWV retrieval, a group of coefficients for the entire CWV range needed to be calculated to ensure the spatial continuity of the LST product. Table 1 displays the coefficients in different CWV sub-ranges and the root-mean-square error (RMSE) of the temperature that are estimated based on the simulation data. The table shows a significant variation in the coefficients with the CWV sub-ranges, particularly in the heavy CWV loading. The RMSE was smaller than the variation from $0.34 \mathrm{~K}$ to $0.93 \mathrm{~K}$, which increased as the CWV increased.

Table 1. The coefficients $b_{k}(\mathrm{k}=0,1, \ldots 7)$ in different atmospheric column water vapor (CWV) sub-ranges and the root-mean-square error (RMSE) of the temperature estimated based on the simulation data.

\begin{tabular}{|c|c|c|c|c|c|c|c|c|c|}
\hline $\begin{array}{c}\text { CWV } \\
\left(\mathrm{g} / \mathrm{cm}^{2}\right)\end{array}$ & $\mathbf{b}_{0}$ & $\mathbf{b}_{1}$ & $\mathbf{b}_{2}$ & $\mathbf{b}_{3}$ & $\mathbf{b}_{4}$ & b5 & $b_{6}$ & $\mathbf{b}_{7}$ & RMSE \\
\hline$[0.0,2.5]$ & -2.78009 & 1.01408 & 0.15833 & -0.34991 & 4.04487 & 3.55414 & -8.88394 & 0.09152 & $0.34 \mathrm{~K}$ \\
\hline$[2.0,3.5]$ & 11.00824 & 0.95995 & 0.17243 & -0.28852 & 7.11492 & 0.42684 & -6.62025 & -0.06381 & $0.60 \mathrm{~K}$ \\
\hline$[3.0,4.5]$ & 9.62610 & 0.96202 & 0.13834 & -0.17262 & 7.87883 & 5.17910 & -13.26611 & -0.07603 & $0.71 \mathrm{~K}$ \\
\hline$[4.0,5.5]$ & 0.61258 & 0.99124 & 0.10051 & -0.09664 & 7.85758 & 6.86626 & -15.00742 & -0.01185 & $0.86 \mathrm{~K}$ \\
\hline$[5.0,6.3]$ & -0.34808 & 0.98123 & 0.05599 & -0.03518 & 11.96444 & 9.06710 & -14.74085 & -0.20471 & $0.93 \mathrm{~K}$ \\
\hline$[0.0,6.3]$ & -0.41165 & 1.00522 & 0.14543 & -0.27297 & 4.06655 & -6.92512 & -18.27461 & 0.24468 & $0.87 \mathrm{~K}$ \\
\hline
\end{tabular}

To investigate the error details from the algorithm, we further presented the histograms of the temperature difference between the actual $T_{s}$ in the simulated dataset and the $T_{s}$ estimated through the SW algorithm using the coefficients (see Table 1) of the $5 \mathrm{CWV}$ sub-ranges. In those figures, the temperature difference evidently fell in the ranges of $[-1.0,1.0] \mathrm{K}$, which covered about $97.92 \%, 94.42 \%, 91.67 \%$, $86.77 \%, 75.99 \%$ and $92.11 \%$ of the total cases in Figure $2 \mathrm{a}-\mathrm{f}$, respectively. The maximum temperature error was about $-3.09 \mathrm{~K}$ (see Figure 2e), which corresponds to the heavy CWV content. In the case of the entire water vapor range, the RMSE was about $0.87 \mathrm{~K}$. 

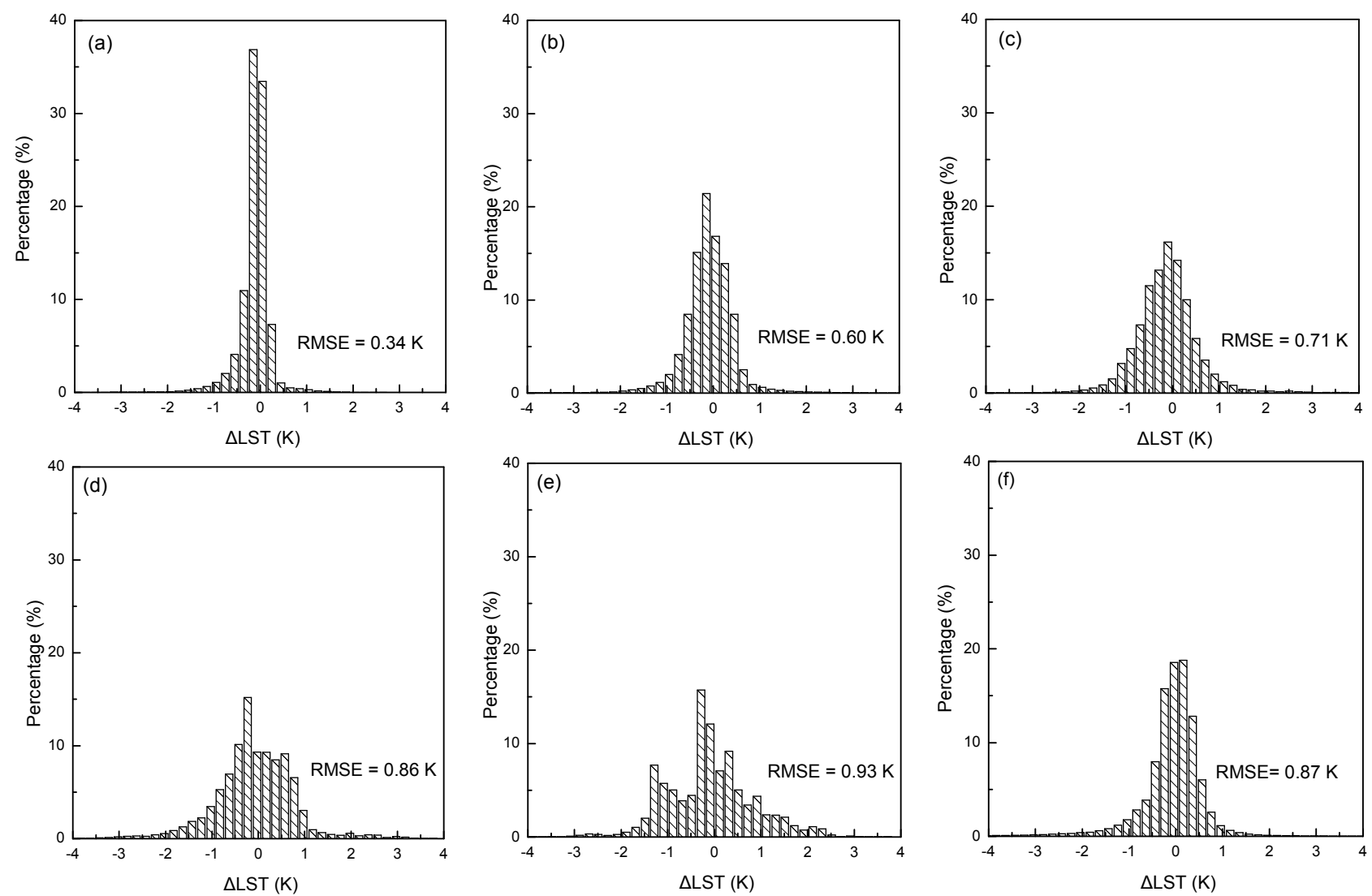

Figure 2. Histograms of temperature difference between the actual $T_{\mathrm{s}}$ and the $\mathrm{T}_{\mathrm{s}}$ estimated using the split-window algorithm; (a) for CWV $\in[0.0,2.5]$; (b) for CWV $\in[2.0,3.5]$; (c) for $\mathrm{CWV} \in[3.0,4.5]$; (d) for $\mathrm{CWV} \in[4.0,5.5]$; (e) for $\mathrm{CWV} \in[5.0,6.3]$; (f) for $\mathrm{CWV} \in[0.0,6.3] \mathrm{g} / \mathrm{cm}^{2}$. CWV: Column Water Vapor, RMSE: Root-Mean-Square Error, $\Delta \mathrm{LST}$ : actual $\mathrm{T}_{\mathrm{s}}$ and the $\mathrm{T}_{\mathrm{s}}$ estimated using the split-window algorithm.

\subsection{Determination of LSES}

The classification-based emissivity method (CBEM) [23,27-29] that estimated LSEs from emissivity look-up tables (LUT) according to conventional land cover classification information was applied in this study to obtain LSEs for the SW algorithm. The CBEM is the simplest method in terms of processing, and this method can provide accurate LSEs for LST retrieval as long as the land surfaces are accurately classified and each class has familiar LSEs. The Finer Resolution Observation and Monitoring of Global Land Cover (FROM-GLC), which was the first $30 \mathrm{~m}$ resolution global land cover map generated from numerous Landsat TM and ETM+ data [30], is newly released to the public and can be downloaded freely. The FROM-GLC contains 10 types of land covers at level-1, namely, cropland, forest, grassland, shrubland, wetland, waterbody, tundra, impervious, barren land and snow-ice. Table 2 lists the resultant classification scheme with a level-2 hierarchy, which involves the cover-type end-component only. Compared with other popular global land covers, such as the International Geosphere-Biosphere Program (IGBP) [31,32], the FROM-GLC considers the impervious urban class. The high resolution of the FROM-GLC, which combines $100 \mathrm{~m}$ resolution TIRS data can significantly improve the accuracy of LSEs. 
Table 2. Land cover schemes in FROM-GLC (Finer Resolution Observation and Monitoring of Global Land Cover) at levels 1 and 2 and their components.

\begin{tabular}{|c|c|c|c|c|}
\hline \multicolumn{2}{|c|}{ Land Cover (Emissivity Class) } & \multirow{2}{*}{ Models } & \multicolumn{2}{|c|}{ Component Description } \\
\hline Level-1 Type & Level-2 Type & & Vegetation Type & Ground Type \\
\hline \multirow{3}{*}{ Cropland } & Rice fields & \multirow{3}{*}{ Vol: $\mathrm{bF}=0.0-0.2$} & Gr. Veg & Mollisols, Liquid Water \\
\hline & Greenhouse farming & & Gr. Veg & Mollisols, Liquid Water \\
\hline & Other croplands & & Gr. Veg & Mollisols \\
\hline \multirow{4}{*}{ Forest } & Broadleaf forests & \multirow{4}{*}{ Vol: $b F=0.7-5.0$} & Bdlf & Alfisols, Spodosols \\
\hline & Needleleaf forests & & Ndle & Alfisols, Spodosols \\
\hline & Mixed forests & & Bdlf, Ndle & Alfisols, Spodosols \\
\hline & Orchards & & Bdlf & Alfisols, Spodosols \\
\hline \multirow{2}{*}{ Grasslands } & Pastures & \multirow{2}{*}{ Vol: $\mathrm{bF}=1.2-5.0$} & Gr. Veg & Aridisols, Gr. Veg, Tree and Bush \\
\hline & Other grasslands & & Gr. Veg & Aridisols, Gr. Veg, Tree and Bush \\
\hline Shrublands & - & Vol: $b F=1.2-5.0$ & Bdlf, Ndle & Aridisols, Gr. Veg, Tree and Bush \\
\hline \multirow{2}{*}{ Wetlands } & Marshland & \multirow{2}{*}{ Spec: $\sigma=0.2$} & - & Alfisols, Gr. Veg and Water \\
\hline & Mudflats & & - & Alfisols, Gr. Veg and Water \\
\hline \multirow{4}{*}{ Waterbodies } & Lake & \multirow{4}{*}{ Spec: $\sigma=0.2$} & - & Liquid Water \\
\hline & Reservoir/Pond & & - & Liquid Water \\
\hline & River & & - & Liquid Water \\
\hline & Ocean & & - & Liquid Water \\
\hline \multirow{2}{*}{ Tundra } & Shrub and Brush Tundra & \multirow{2}{*}{ Vol: $b F=0.35-0.7$} & Bdlf, Ndle & Aridisols, Gr. Veg, Tree and Bush \\
\hline & Herbaceous Tundra & & Gr. Veg & Aridisols, Gr. Veg, Tree and Bush \\
\hline \multirow{2}{*}{ Impervious } & Impervious-high albedo & \multirow{2}{*}{ Vol: $b F=0.2-0.5$} & Gr. Veg & Paving concrete \\
\hline & Impervious-low albedo & & Gr. Veg & Paving asphalt \\
\hline \multirow{6}{*}{ Barren Land } & Dry salt flats & \multirow{6}{*}{ Vol: $\mathrm{bF}=0.0-0.2$} & Sn.Veg & Salty soil \\
\hline & Sandy areas & & Sn.Veg & Sand soil \\
\hline & Bare exposed rock & & Sn.Veg & Coarse sandstone \\
\hline & Bare herbaceous croplands & & Sn.Veg & Aridisols, Gr. Veg, Tree and Bush \\
\hline & Dry lake/river bottom & & Sn.Veg & Aridisols, Gr. Veg, Tree and Bush \\
\hline & Other barren lands & & Sn.Veg & Aridisols, Gr. Veg, Tree and Bush \\
\hline \multirow{2}{*}{ Snow and ice } & Snow & \multirow{2}{*}{ Spec: $\sigma=0.2$} & - & Snow \\
\hline & & & - & Ice \\
\hline
\end{tabular}

Ndle. $=$ Needle, Bdlf. $=$ Broadleaf, Gr. $=$ Green, Sn. $=$ Senescent, Veg. $=$ Vegetation; Vol $=$ Volumetric kernel BRDF Model, Spec $=$ Specular kernel BRDF Model; $b F=$ Optical depth; $\sigma=$ Surface roughness .

According to the classification scheme in Table 2, three BRDF kernel (bi-directional distribution function) models, i.e., geometrical, volumetric and specular models [24,27], were used to calculate the scene emissivity for each land cover. Considering the variation of the biophysical and structural characteristics in the various land covers, different combinations of these BRDF kernel models were applied for the various land covers. According to the FROM-GLC, we classified 20 land cover types (level-2) into the volumetric BRDF kernel model, and the other 8 types were classified into the specular BRDF kernel model. Given that sparse vegetation was not in the FROM-GLC, we did not consider the geometrical BRDF kernel model. The details are shown in Table 2. Moreover, in this table, the parameter $b F=-\ln (1-A)$, where $A$ is the projected fractional area of the volumetric portion (i.e., vegetation cover). 
The volumetric model can be applied in the $50 \%$ to $100 \%$ coverage range for trees, crops and shrubs, and over the entire range for grasses. $\sigma$ is the surface roughness and is equal to 0.2 .

The vegetation and ground emissivity spectra were selected from the MODIS University of California, Santa Barbara (UCSB) Emissivity Library [33] on the composition of the level-1 and level-2 products in the FROM-GLC, and the spectra were entered in the BRDF kernel models to obtain the scene emissivity. Although the emissivity was reported to vary with the view zenith angle, we found that the angular variation of emissivity was insignificant in the FOV (i.e., 15 degrees) of the TIRS instrument and can be disregarded without leading to obvious errors to the LST. Moreover, we used Fraction of vegetation cover (FVC) to obtain land surface emissivity (LSE) of land cover with temporal variation. It is well known that LSE is a key parameter used in land surface dynamics and varies with the composition of land cover, especially for the natural surface. Assumption that pixel LSE is a linear combination of vegetation and bare soil emissivities of the different land covers, the FVC is estimated from the NDVI, calculated from the red and near-infrared reflectance of Operational Land Imager, another payload on Landsat8, by using the method proposed by Carlson (1997) and Sobrino (2001) [34,35]. Finally, an emissivity LUT based on the land cover and FVC was established, and the average band emissivities for the TIRS bands 10 and 11 over different land covers are listed in Table 3. During the retrieval process, the land covers of the pixel from the FROM-GLC and FVC that were calculated from the Normalized Difference Vegetation Index (NDVI) was used to determine the emissivity LUT to obtain the pixel channel emissivities.

Table 3. Average emissivity for two TIRS (Thermal Infrared Sensor) channels at different land covers of FROM-GLC (Finer Resolution Observation and Monitoring of Global Land Cover)

\begin{tabular}{ccc}
\hline \multirow{2}{*}{ Emissivity Class } & \multicolumn{2}{c}{ Mean } \\
\cline { 2 - 3 } & TIRS-10 & TIRS-11 \\
\hline Cropland & 0.971 & 0.968 \\
Forest & 0.995 & 0.996 \\
Grasslands & 0.970 & 0.971 \\
Shrublands & 0.969 & 0.970 \\
Wetlands & 0.992 & 0.998 \\
Waterbodies & 0.992 & 0.998 \\
Tundra & 0.980 & 0.984 \\
Impervious & 0.973 & 0.981 \\
Barren Land & 0.969 & 0.978 \\
Snow and ice & 0.992 & 0.998 \\
\hline
\end{tabular}

\subsection{Determination of Atmospheric $C W V$}

Inspired by several previous studies [36-39], a modified split-window covariance and variance ratio (MSWCVR) method was developed to retrieve CWV from the TIRS data. With a vital assumption that the atmosphere is unchanged over the neighboring pixels, the MSWCVR method relates the atmospheric CWV to the ratio of the upward transmittances in two thermal infrared bands, whereas the transmittance ratio can be calculated based on the TOA brightness temperatures of the two bands. Considering $N$ adjacent pixels, the CWV in the MSWCVR method is estimated as 


$$
\begin{gathered}
c w v=c_{0}+c_{1} \cdot\left(\tau_{j} / \tau_{i}\right)+c_{2} \cdot\left(\tau_{j} / \tau_{i}\right)^{2} \\
\tau_{j} / \tau_{i} \approx R_{j i}=\sum_{k=1}^{N}\left(T_{i, k}-\bar{T}_{i}\right)\left(T_{j, k}-\bar{T}_{j}\right) / \sum_{k=1}^{N}\left(T_{i, k}-\bar{T}_{i}\right)^{2}
\end{gathered}
$$

In Equation (3a), $c_{0}, c_{1}$ and $c_{2}$ are the coefficients obtained from the simulated data; $\tau$ is the band effective atmospheric transmittance; $N$ is the number of adjacent pixels (always excluding water and cloud pixels) in a spatial window size $\mathrm{n}$ (i.e., $N=n \times n) ; T_{i, k}$ and $T_{j, k}$ are the respective brightness temperatures (K) of bands $i$ and $j$ at the TOA level for the $k$ th pixel; and $\overline{T_{i}}$ and $\overline{T_{j}}$ are the mean or median brightness temperatures of the $N$ pixels for the two bands. Using the aforementioned 946 cloud-free TIGR atmospheric profiles, we first used the new high accurate atmospheric radiative transfer model MODTRAN 5.2 to simulate the band effective atmospheric transmittance, and then we obtained the coefficients through regression, which resulted in $c_{0}=-9.674, c_{1}=0.653$ and $c_{2}=9.087$. The model analysis indicated that this method will obtain a CWV RMSE of about $0.5 \mathrm{~g} / \mathrm{cm}^{2}$. The details about the CWV retrieval can be found in [40].

\section{Sensitivity Analysis}

\subsection{Sensitivity Analysis to Instrument Noises}

The noise-equivalent-change-in-temperature (NE $\Delta \mathrm{T})$ of the TIRS instrument was designed as $0.80 \mathrm{~K}$ at $240 \mathrm{~K}, 0.4 \mathrm{~K}$ at $300 \mathrm{~K}$ and $0.27 \mathrm{~K}$ at $360 \mathrm{~K}$ for channel 10 , and $0.71 \mathrm{~K}$ at $240 \mathrm{~K}, 0.4 \mathrm{~K}$ at $300 \mathrm{~K}$ and $0.29 \mathrm{~K}$ at $360 \mathrm{~K}$ for channel 11 [41]. However, this $\mathrm{NE} \Delta \mathrm{T}$ was much greater than that of the similar thermal infrared bands on orbit in the MODIS and AHVRR $[42,43]$ and caused significant uncertainty in the land surface temperature retrieval. Fortunately, Ren recently estimated the radiometric noise for the two bands of the TIRS by using images over uniform ground areas, where the actual NE $\Delta \mathrm{T}$ of the two bands was found to be about $0.1 \mathrm{~K}$, which was better than the design specification [44].

To investigate the effect of noise on the LST error, we added a Gaussian noise with a zero mean and a standard deviation equal to $2 \times \mathrm{NE} \Delta \mathrm{T}(=0.1,0.2$ and $0.4 \mathrm{~K})$ to the TOA brightness temperatures $T_{i}$ and $T_{j}$ in Equation (2). For CWV $\in[0,2.5]$ considering most parts of the 946 atmospheric profiles, we selected the coefficients in this CWV range (see Table 1) as examples to check the variation of the RMSEs affected by the given NE $\Delta \mathrm{T}$. Thus, the LST error was $0.355 \mathrm{~K}$ for NE $\Delta \mathrm{T}=0.1 \mathrm{~K}, 0.397 \mathrm{~K}$ for NE $\Delta \mathrm{T}=0.2 \mathrm{~K}$ and $0.531 \mathrm{~K}$ for $\mathrm{NE} \Delta \mathrm{T}=0.4 \mathrm{~K}$. Compared with the LST error (i.e., $0.34 \mathrm{~K}$ ) for the no instrument noise, $\mathrm{NE} \Delta \mathrm{T}=0.1 \mathrm{~K}$ contributed only $4.5 \%$ of the error in the retrieved LST, whereas NE $\Delta \mathrm{T}=0.2 \mathrm{~K}$ contributed about $16.8 \%$ and $\mathrm{NE} \Delta \mathrm{T}=0.4 \mathrm{~K}$ contributed up to $56.3 \%$.

\subsection{Sensitivity Analysis to LSES}

According to Equation (2), $\frac{1-\varepsilon}{\varepsilon}$ and $\frac{\Delta \varepsilon}{\varepsilon^{2}}$ determined the sensitivity from the LSE uncertainties, which can be expressed as

$$
\begin{aligned}
& \alpha=b_{2} \frac{T_{i}+T_{j}}{2}+b_{5} \frac{T_{i}-T_{j}}{2} \\
& \beta=b_{3} \frac{T_{i}+T_{j}}{2}+b_{6} \frac{T_{i}-T_{j}}{2}
\end{aligned}
$$


To determine the algorithm sensitivities in the different CWV sub-ranges, we consider the coefficients in all the CWV sub-ranges. By using the same regression method mentioned in Section 2.2 and by combining with Equation (4), we can obtain the variation of $\alpha$ and $\beta$. Table 4 shows the range, mean and standard derivation of $\alpha$ and $\beta$ for all the sub-ranges.

Table 4. The values of $\alpha$ and $\beta$ in Equations (4a) and (4b). $\alpha$ and $\beta$ are coefficients of $\frac{1-\varepsilon}{\varepsilon}$ and $\frac{\Delta \varepsilon}{\varepsilon^{2}}$, respectively, mentioned in Equations (4a) and (4b).

\begin{tabular}{|c|c|c|c|c|c|c|c|c|c|c|}
\hline \multirow{2}{*}{$\begin{array}{c}\begin{array}{c}\text { CWV Sub-Ranges } \\
\left(\mathrm{g} / \mathrm{cm}^{2}\right)\end{array} \\
\text { Variables }\end{array}$} & \multicolumn{2}{|c|}{$[0.0,2.5]$} & \multicolumn{2}{|c|}{$[2.0,3.5]$} & \multicolumn{2}{|c|}{$[3.0,4.5]$} & \multicolumn{2}{|c|}{$[4.0,5.5]$} & \multicolumn{2}{|c|}{$[5.0,6.3]$} \\
\hline & $\alpha$ & $\beta$ & $\alpha$ & $\beta$ & $\alpha$ & $\beta$ & $\alpha$ & $\beta$ & $\alpha$ & $\beta$ \\
\hline Range of Value (K) & $\begin{array}{l}{[30.70,} \\
61.38]\end{array}$ & $\begin{array}{c}{[-138.62} \\
-66.76]\end{array}$ & $\begin{array}{l}{[45.77,} \\
56.46]\end{array}$ & $\begin{array}{c}{[-112.25} \\
-68.18]\end{array}$ & $\begin{array}{l}{[30.57,} \\
60.88]\end{array}$ & $\begin{array}{l}{[-99.19} \\
-28.91]\end{array}$ & $\begin{array}{l}{[20.94,} \\
54.83]\end{array}$ & $\begin{array}{l}{[-81.41,} \\
-10.97]\end{array}$ & $\begin{array}{l}{[12.73,} \\
46.30]\end{array}$ & $\begin{array}{r}{[-58.40} \\
-4.40]\end{array}$ \\
\hline Mean $(\mathrm{K})$ & 42.29 & -93.57 & 51.20 & -90.02 & 46.03 & -64.04 & 38.20 & -47.09 & 30.53 & -33.11 \\
\hline Standard deviation $(\mathrm{K})$ & 4.00 & 9.20 & 1.82 & 6.60 & 4.95 & 11.41 & 6.08 & 12.65 & 7.10 & 11.34 \\
\hline
\end{tabular}

Based on Table 4 , the absolute value of $\alpha$ and $\beta$ notably increased as the CWV in the atmosphere increased, which indicated better convergence of the sensitivities of LST to $\frac{1-\varepsilon}{\varepsilon}$ and $\frac{\Delta \varepsilon}{\varepsilon^{2}}$ in a wet atmospheric condition compared with those in a dry atmospheric condition. According to Equation (2), the combined uncertainty from $\frac{1-\varepsilon}{\varepsilon}$ and $\frac{\Delta \varepsilon}{\varepsilon^{2}}$ contributed to the LST error $\delta$ LST, which can be written as

$$
\delta L S T=\sqrt{\alpha^{2} \delta\left(\frac{1-\varepsilon}{\varepsilon}\right)^{2}+\beta^{2} \delta\left(\frac{\Delta \varepsilon}{\varepsilon^{2}}\right)^{2}}
$$

Table 5. LST (Land Surface Temperature) errors caused by $1 \%$ uncertainties in LSEs (Land Surface Emissivities) for different ranges of CWV (Column Water Vapor).

\begin{tabular}{cccccc}
\hline \multirow{2}{*}{ LST Error $(\mathbf{K})$} & \multicolumn{5}{c}{$\mathbf{C W V ~}\left(\mathbf{g} / \mathbf{c m}^{\mathbf{2}}\right)$} \\
\cline { 2 - 6 } & {$[\mathbf{0 . 0}, \mathbf{2 . 5}]$} & {$[\mathbf{2 . 0}, \mathbf{3 . 5}]$} & {$[\mathbf{3 . 0}, \mathbf{4 . 5}]$} & {$[\mathbf{4 . 0}, \mathbf{5 . 5}]$} & {$[\mathbf{5 . 0}, \mathbf{6 . 3}]$} \\
\hline Range of Value & {$[0.73,1.52]$} & {$[0.82,1.25]$} & {$[0.42,1.16]$} & {$[0.24,0.98]$} & {$[0.13,0.75]$} \\
Mean & 1.02 & 1.04 & 0.79 & 0.61 & 0.45 \\
Standard deviation & 0.10 & 0.06 & 0.12 & 0.13 & 0.13 \\
\hline
\end{tabular}

Table 5 shows that the LST error was caused by $1 \%$ of the LSE uncertainties for the different CWV ranges. From this table, the LST error was determined as $[0.73,1.52] \mathrm{K}$ with a mean of $1.02 \mathrm{~K}$ and a standard deviation of $0.10 \mathrm{~K}$ for the CWV sub-range of $[0.0,2.5] \mathrm{g} / \mathrm{cm}^{2}$. The error generally decreased as the CWV increased, and the minimum was obtained for the highest atmospheric condition consequently. In addition, the range of the LST error in the wet atmospheric condition was narrower than that in the dry atmospheric condition. This finding indicates that in wet atmospheric conditions, the dominant factor that affects the LST error is the uncertainty from the atmospheric information, rather than from that of the surface conditions. In this case, the LST retrieval was insensitive to the error included in the LSEs.

\subsection{Sensitivity Analysis to the Atmospheric $C W V$}

As shown in Figure 2, the CWV is important in improving the accuracy of LST retrieval. However, we did not directly use the CWV in Equation (2) to estimate the LST, but we applied this parameter to 
determine the algorithm coefficients (see Table 1). As mentioned in Section 3.3, the CWV retrieval had an error of about $0.5 \mathrm{~g} / \mathrm{cm}^{2}$ theoretically. Thus, misclassifying CWV from the correct sub-range to the incorrect sub-range was possible, which can result in wrong coefficients for the SW algorithm. Table 6 lists the LST errors caused by using the wrong coefficients in the adjacent CWV sub-ranges. Given that the CWV error varies from $-0.5 \mathrm{~g} / \mathrm{cm}^{2}$ to $0.5 \mathrm{~g} / \mathrm{cm}^{2}$, we considered only the cases of misclassifying CWV in the adjacent CWV sub-ranges. Thus, for a true CWV value of $2.6 \mathrm{~g} / \mathrm{cm}^{2}$, the retrieved water vapor value may be ranged in $[0.0,2.5],[2.0,3.5]$ or $[3.0,4.5] \mathrm{g} / \mathrm{cm}^{2}$.

Table 6. LST (Land Surface Temperature) errors caused by using wrong coefficients in adjacent CWV (Column Water Vapor) sub-ranges.

\begin{tabular}{cccccc}
\hline $\mathbf{C W V}\left(\mathbf{g} / \mathbf{c m}^{2}\right)$ & {$[\mathbf{0 . 0}, \mathbf{2 . 5}]$} & {$[\mathbf{2 . 0}, \mathbf{3 . 5}]$} & {$[\mathbf{3 . 0}, \mathbf{4 . 5}]$} & {$[\mathbf{4 . 0}, \mathbf{5 . 5}]$} & {$[\mathbf{5 . 0 , 6 . 3}]$} \\
\hline$[0.0,2.5]$ & $0.34 \mathrm{~K}$ & $1.45 \mathrm{~K}$ & - & - & - \\
{$[2.0,3.5]$} & $1.40 \mathrm{~K}$ & $0.60 \mathrm{~K}$ & $1.40 \mathrm{~K}$ & - & - \\
{$[3.0,4.5]$} & - & $1.34 \mathrm{~K}$ & $0.71 \mathrm{~K}$ & $1.21 \mathrm{~K}$ & - \\
{$[4.0,5.5]$} & - & - & $1.29 \mathrm{~K}$ & $0.86 \mathrm{~K}$ & $2.45 \mathrm{~K}$ \\
{$[5.0,6.3]$} & - & - & - & $1.85 \mathrm{~K}$ & $0.93 \mathrm{~K}$ \\
\hline
\end{tabular}

In Table 6, the diagonal direction shows the LST errors with the correct coefficients in the corresponding CWV sub-ranges, which were similar to the results in Figure 2. The other values are the results from the incorrect coefficients, which are denoted as $\delta L S T_{\text {inc }}$ for convenience in the following discussion. The $\delta L S T_{\text {inc }}$ was less than $1.5 \mathrm{~K}$ with a CWV of less than $4.0 \mathrm{~g} / \mathrm{cm}^{2}$, but $\delta L S T_{\text {inc }}$ increased dramatically with a CWV of more than $4.0 \mathrm{~g} / \mathrm{cm}^{2}$. However, for a CWV in the sub-ranges of [2.5, 3.0], $[3.5,4.0],[4.5,5.0]$ or $[5.5,6.0] \mathrm{g} / \mathrm{cm}^{2}$, the CWV retrieval value using the MSWCVR method may fall in the CWV adjacent sub-ranges, which consequently decreases the LST accuracy. For instance, a CWV is $4.8 \mathrm{~g} / \mathrm{cm}^{2}$ and belongs to a sub-range of $[4.5,5.0] \mathrm{g} / \mathrm{cm}^{2}$. If this CWV is misclassified into [3.5, 4.0], the $\delta L S T_{\text {inc }}$ will be $1.29 \mathrm{~K}$, whereas if this CWV is misclassified into $[5.5,6.0]$, the $\delta L S T_{\text {inc }}$ will reach $2.45 \mathrm{~K}$. To reduce the influence of the CWV error on the LST, for a CWV within the overlap of two adjacent CWV sub-ranges, we first use the coefficients from the two adjacent CWV sub-ranges to calculate the two initial temperatures and then use the average of the initial temperatures as the pixel LST. For example, the LST pixel with a CWV of $2.1 \mathrm{~g} / \mathrm{cm}^{2}$ is estimated by using the coefficients of [0.0, 2.5] and [2.0, 3.5]. This process initially reduces the $\delta L S T_{\text {inc }}$ and improves the spatial continuity of the LST product.

\subsection{Comparison amongst Different Split-Window Algorithms}

To date, two other SW algorithms were proposed for LST retrieval from TIRS data. Jiménez-Muñoz et al. (2014) [45] presented an SW algorithm based on the structure suggested by Sobrino et al. (1996) [46], and Rozenstein et al. (2014) [47] utilized a first-order Taylor-series linearization of the radiative transfer equation and addressed a general form based on the work of Qin et al. (2001). The formats of the current SW algorithms are expressed as follows:

Jiménez-Muñoz et al.:

$$
T_{s}=T_{i}+d_{1}\left(T_{i}-T_{j}\right)+d_{2}\left(T_{i}-T_{j}\right)^{2}+d_{0}+\left(d_{3}+d_{4} w\right)(1-\varepsilon)+\left(d_{5}+d_{6} w\right) \Delta \varepsilon
$$

Rozenstein et al.:

$$
T_{s}=T_{i}+f_{0}\left(T_{i}-T_{j}\right)+e_{1} \cdot f_{1}+e_{2} \cdot f_{2}+e_{3} \cdot f_{1} \cdot T_{i}-e_{4} \cdot f_{2} \cdot T_{j}
$$


In the above equations, $d_{k}(k=0,1 \ldots 6)$ and $e_{k}(k=1,2,3,4)$ are the algorithm coefficients; $w$ is the $\mathrm{CWV} ; \varepsilon$ and $\Delta a$ are the average emissivity and emissivity difference of two adjacent thermal channels, respectively, which are similar to Equation (2); and $f_{k}(k=0$ and 1) is related to the influence of the atmospheric transmittance and emissivity, i.e., $f_{k}=f\left(\varepsilon i, \varepsilon_{j}, \tau_{i}, \tau_{j}\right)$. Note that the algorithm (Equation (6a)) proposed by Jiménez-Muñoz et al. added CWV directly to estimate LST. Rozenstein et al. used CWV to estimate the atmospheric transmittance $\left(\tau_{i}, \tau_{j}\right)$ and optimize retrieval accuracy explicitly. Therefore, if the atmospheric CWV is unknown or cannot be obtained successfully, neither of the two algorithms in Equations (6a) and (6b) will work. By contrast, although our algorithm also needs CWV to determine the coefficients, this algorithm still works for unknown CWVs because the coefficients are obtained regardless of the CWV, as shown in Table 1. We first obtained the coefficients of Equations (6a) and (6b) using the same simulated dataset in our algorithm development, and then we analyzed the difference between the SW algorithms. Table 7 presents the LST errors caused by the different algorithms for various CWV sub-ranges. From this table, we know that the errors of all the algorithms were close to one another for a CWV of less than $3.5 \mathrm{~g} / \mathrm{cm}^{2}$, which is much less than $1.0 \mathrm{~K}$. However, under wet atmospheric conditions, the LST error increased quickly as the CWV increased, especially for the algorithm of Rozenstein et al., Jiménez-Muñoz's algorithm had similar results with our algorithm. Moreover, we added an uncertainty of $\pm 0.5 \mathrm{~g} / \mathrm{cm}^{2}$ to the CWV, and we found that the LST error was about $0.8 \mathrm{~K}$ for the CWV of - of $\mathrm{t}$ tha ${ }^{2}$ and $1.1 \mathrm{~K}$ for the $\mathrm{CWV}$ of $+0.5 \mathrm{~g} / \mathrm{cm}^{2}$ for the algorithm of Jiménez-Muñoz et al.; the results were somewhat better than those of our algorithm, as shown in Table 7, probably because of the direct usage of CWV in the algorithm of Jiménez-Muñoz et al. (Equaiton (6a)) to reduce the influence of the CWV on the LST retrieval accuracy. As stated above, all three algorithms relied on the CWV input and were impractical without this parameter. To deal with this potential problem, our algorithm also obtained the coefficients in Equation (2) for the entire CWV range, and this group of coefficients only resulted in an LST error of about $0.87 \mathrm{~K}$ for all the CWV, about $0.46 \mathrm{~K}$ for the CWV sub-range of $[0.0,2.5] \mathrm{g} / \mathrm{cm}^{2}$ and about $1.11 \mathrm{~K}$ for a CWV of less than $3.5 \mathrm{~g} / \mathrm{cm}^{2}$. This CWV range contains most cases of atmospheric moisture in polar, mid-latitude and tropical profiles. Therefore, compared with the other two algorithms, our algorithm is more practical and can even obtain LST with high accuracy for cases even without known CWV information.

Table 7. LST (Land Surface Temperature) error for different split-window (SW) algorithms at different sub-ranges of CWV (Column Water Vapor). The second, third and fourth columns correspond to the RMSEs (Root-Mean-Square Errors) of Jiménez-Muñoz et al., Rozenstein et al., and our algorithm, while the last column is RMSE from our algorithm using the coefficients derived from all water vapor range $[0,6.3] \mathrm{g} / \mathrm{cm}^{2}$ when no CWV information can be obtained.

\begin{tabular}{ccccc}
\hline $\mathbf{C W V}\left(\mathbf{g} / \mathbf{c m}^{2}\right)$ & Jiménez-Muñoz & Rozenstein & \multicolumn{2}{c}{ SW in This Paper } \\
\hline$[0.0,2.5]$ & $0.46 \mathrm{~K}$ & $0.32 \mathrm{~K}$ & $0.34 \mathrm{~K}$ & $0.46 \mathrm{~K}$ \\
{$[2.0,3.5]$} & $0.51 \mathrm{~K}$ & $0.56 \mathrm{~K}$ & $0.60 \mathrm{~K}$ & $1.11 \mathrm{~K}$ \\
{$[3.0,4.5]$} & $0.71 \mathrm{~K}$ & $0.79 \mathrm{~K}$ & $0.71 \mathrm{~K}$ & $2.00 \mathrm{~K}$ \\
{$[4.0,5.5]$} & $0.87 \mathrm{~K}$ & $1.32 \mathrm{~K}$ & $0.86 \mathrm{~K}$ & $2.33 \mathrm{~K}$ \\
{$[5.0,6.3]$} & $0.93 \mathrm{~K}$ & $1.26 \mathrm{~K}$ & $0.93 \mathrm{~K}$ & $3.13 \mathrm{~K}$ \\
{$[0.0,6.3]$} & $0.72 \mathrm{~K}$ & $1.25 \mathrm{~K}$ & $0.87 \mathrm{~K}$ & $0.87 \mathrm{~K}$ \\
\hline
\end{tabular}




\section{Application of the Split-Window Algorithm}

Based on the above discussions, the input parameters to drive the new SW algorithm includes the brightness temperatures ( $T_{i}$ and $T_{j}$ ) of the two adjacent bands of the TIRS, FROM-GLC land cover products and emissivity lookup table, which are a fraction of the FVC that can be estimated from the red and near-infrared reflectance of the Operational Land Imager (OLI). These parameters can be easily obtained, which makes our algorithm generally operational in practice. Figure 3 shows the main flowchart of the LST retrieval LST from the TIRS data, where the clouds in the images are eliminated by using the band quality files along with the OLI and TIRS data, which are consequently removed before the LST retrieval. The output can contain LST products and emissivity images in the two channels and in the CWV product.

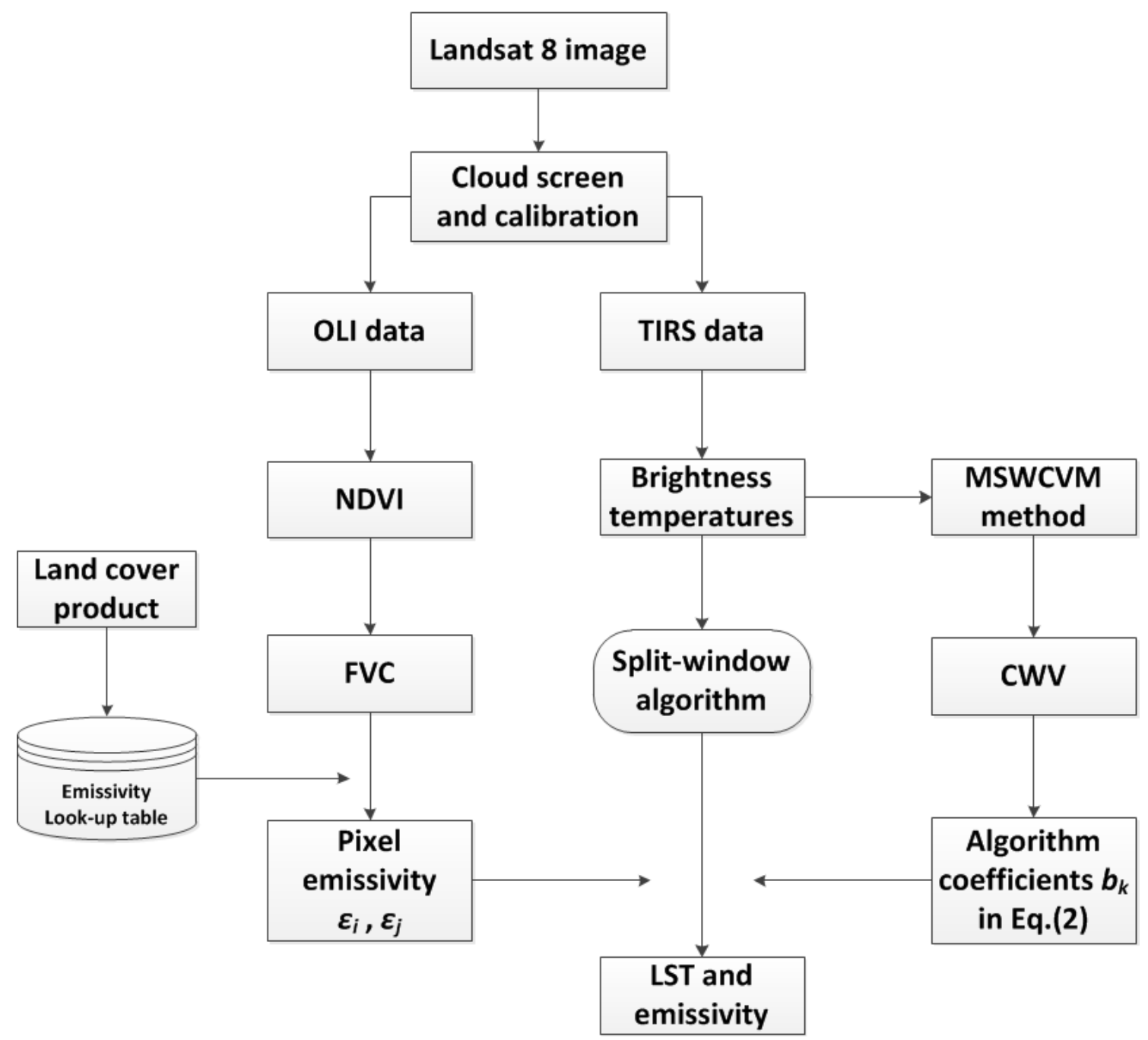

Figure 3. The main flowchart of retrieving LST (Land Surface Temperature) from Landsat 8 image. OLI: Operational Land Imager; TIRS: Thermal Infrared Sensor; NDVI: Normalized Different Vegetation Index; FVC: Fraction of Vegetation Cover; MSWCVM: Modified Split-Window Covariance and Variance Ratio; CWV: Column Water Vapor.

Based on Figure 3, we applied the new SW algorithm to retrieve LST in two different locations: around the Beijing urban area (orbit path $=132$, row $=32$, acquired date: 12 May 2013) in China, and in northwest 
China (orbit path $=143$ row $=31$, acquired date: 25 June 2013), where the atmosphere is always very dry and most of the land surface is covered by desert or Gobi. Figure $4 \mathrm{a}$ and d display the false color images of the two locations, which are generated from the OLI near-infrared, red and green bands. The red pixels depict vegetated areas, the black pixels indicate water, and the grey and light blue pixels represent barren surface, such as urban impervious areas and Gobi Desert areas. The clouds are shown in white. Figure $4 \mathrm{~b}, \mathrm{e}$ shows the retrieved LST in the two locations, and the white colour in the images represents the invalid pixels caused by the clouds. Figure 4c,f are the LST histograms.

Based on Figure $4 b$, the temperatures of the urban impervious surface are higher than those around the vegetated surface and water bodies, which consequently lead to the urban heat island effect. In Figure 4e, the temperatures in the deserts are much higher than those in the oasis areas and water bodies, and the temperature difference in this area can reach up to 20 or $30 \mathrm{~K}$. In this region, the LST is highly correlated to the surface types and soil moistures, and then becomes a significant indicator of the environmental conditions. Compared with the histograms shown in Figure $4 \mathrm{c}$ and $\mathrm{f}$, the spatial temperature difference of Figure $4 \mathrm{~d}$ is more significant than that of Figure $4 \mathrm{a}$, which is probably because the atmospheric moisture in northwest China is generally low from the lack of surface evapotranspiration and input water vapor from other places; the LST is mainly determined by the surface conditions, whereas the regions of Figure $4 \mathrm{a}$ has a relatively higher water vapor, and the spatial temperature difference is smoothened by the atmospheric effect.
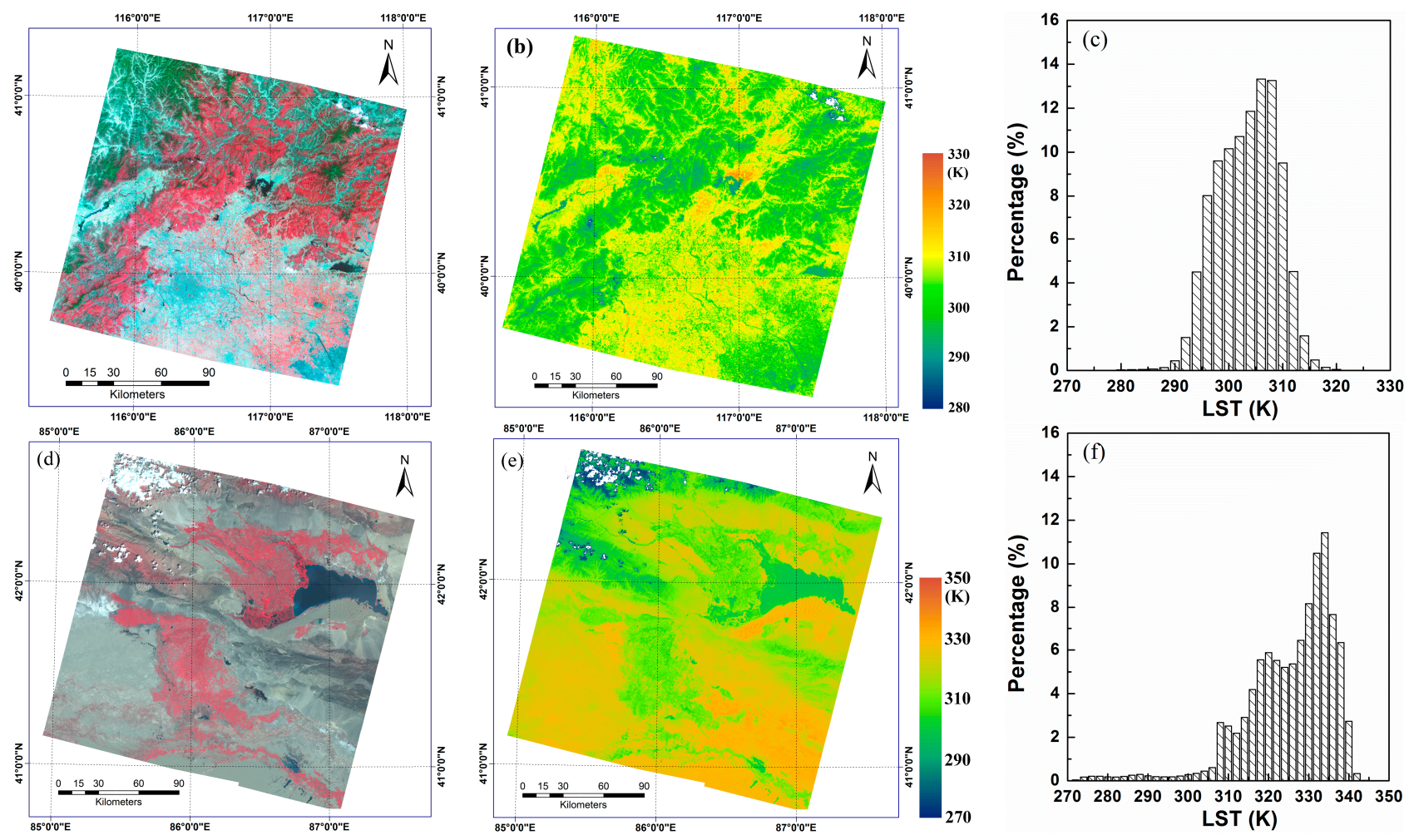

Figure 4. The LST (Land Surface Temperature) retrieved from TIRS (Thermal Infrared Sensor) data at urban area of Beijing city and Gobi in northwest China. (a) and (d) are the false color images; (b) and (e) are the retrieved LST; while (c) and (f) present LST histograms. 
Note that, the validation of the LST estimated from the Landsat 8 TIRS data was not conducted in this paper because it is discussed in another separate paper by using in situ measured temperature synchronously with Landsat 8 overpass in several uniform surface and also with some other products, such as MODIS and ASTER LST products.

\section{Discussions}

As stated above, this paper proposed a practical algorithm to obtain LST from Landsat 8, but for its good performance several attentions should be paid. First, as pointed by some studies [44,49], data gap existed in some of current TIRS images because of the uncertainly of pixel-to-pixel radiometric calibration. As a result, the used water vapor will show spatial discontinuity, and consequently, the LST products will show some obvious blocks in their images. Therefore, it is very necessary and important to investigate the pixel-to-pixel radiometric calibration the TIRS image. Besides, the spatial scales of land cover product $(30 \mathrm{~m})$, water vapor $(1 \mathrm{~km})$, TIRS pixel $(100 \mathrm{~m})$, and FVC data $(30 \mathrm{~m})$ can reduce the LST retrieval accuracy if spatial mis-registration exists between different input auxiliary data.

As mentioned in Section 2.2, the used 946 TIGR atmospheric profiles is composed of 812 profiles for $\mathrm{CWV} \in[0.0,2.5] \mathrm{g} / \mathrm{cm}^{2}, 100$ profiles for CWV $\in[2.0,3.5] \mathrm{g} / \mathrm{cm}^{2}, 76$ profiles for CWV $\in[3.0,4.5] \mathrm{g} / \mathrm{cm}^{2}$, 36 profiles for $\mathrm{CWV} \in[4.0,5.5] \mathrm{g} / \mathrm{cm}^{2}$ and 15 profiles for $\mathrm{CWV} \in[5.0,6.3] \mathrm{g} / \mathrm{cm}^{2}$. The dry atmosphere takes great part in the used atmospheric profiles, but our algorithm developed several groups of coefficients depending on the CWV sub-ranges, so the current algorithm will not cause significant uncertainty to the final LST retrieval with known CWV, but it will lead some error to the LST result for the cases without input CWV. To reduce this effect, we are trying to find more representative profiles to optimize the current algorithm in the coming future work.

In addition, newly released from U.S. Geological Survey (USGS), discrepancies have been noted between calibrated Landsat 8 TIRS Bands 10 and 11 data and these calibration uncertainty results about more than $2 \mathrm{~K}$ errors compared with surface-water temperature field campaign. Although, the radiometric and geometric refinements have been implemented in thermal infrared band offsets soon and improved the data accuracy to $-2.1 \pm 0.8 \mathrm{~K}$ for band 10 and $-4.4 \pm 1.75 \mathrm{~K}$ for band 11 at a $300 \mathrm{~K}$ brightness temperature respectively, this accuracy still cannot meet the requirements of algorithm application $[48,49]$. Meanwhile, according to the reprocessing campaign results, this uncertainty is scene-dependent and probably related to out-of-field response in the TIRS instrument, and gives us an obstacle in algorithm validation, for we cannot analyze whether errors are caused by TIRS sensor or the algorithm.

\section{Conclusions}

Land surface temperature, as one of the key variables, describes surface states and processes critical in studies of climate, hydrology, ecology and human health. This study proposed a practical split-window algorithm for LST retrieval from the Landsat 8 TIRS data using two thermal infrared channels: CH10 (10.6 $\mu \mathrm{m}$ to $11.2 \mu \mathrm{m})$ and CH1 $1(11.5 \mu \mathrm{m}$ to $12.5 \mu \mathrm{m})$. The new SW algorithm estimated the LST by using a nonlinear combination of brightness temperatures, and the algorithm coefficients were designed to be dependent on water vapor, which was obtained from the TIRS data itself using the MSWCVR method. According to the principle of the CBEM, channel emissivities were obtained from the FROM-GLC products at $30 \mathrm{~m}$, and FVC was calculated from the red and near-infrared images aboard the Landsat 8 . 
The simulation results showed that the new algorithm can obtain LST with an accuracy of better than $1.0 \mathrm{~K}$. A model analysis with respect to the noise that included in the measured brightness temperature, emissivity and water vapor was conducted, and the results showed that the new algorithm was robust in LST retrieval.

Our algorithm was compared with two other existing algorithms, and the results showed that the accuracy of our algorithm was close to that of Jiménez-Muñoz and was better than that of Rozenstein. However, because we used water vapor to determine the coefficients of the SW algorithm rather than directly applying this parameter in the algorithm equations as other algorithms do, and also because we obtained the algorithm coefficients for all the water vapor ranges, the new SW algorithm in this paper was more practical than the two existing algorithms, especially in conditions where the water vapor is unknown. The new SW algorithm was applied to two different regions, and the estimated LST presented higher value in urban and desert areas than the vegetated surface and waterbody. The results further proved the credibility and reliability of our proposed SW algorithm.

Considering the strip problem, ghost signal caused by stray light and a time-varying absolute calibration error for TIRS, the validation exercise is still a tough problem and will be discussed in another separate paper by using ground measured surface temperature at different uniform areas and with other surface temperature products, such as MODIS [6] and ASTER [7] products.

\section{Acknowledgments}

This work was supported by the programs of the National Natural Science Foundation of China (Grant No. 41230747, 41401375, and 41231170), the China Postdoctoral Science Foundation (Grant No. 2014M550551, 2014M550550), and the High Resolution Earth Observation Systems of National Science and Technology Major Projects. The Landsat 8 images were downloaded from USGS image achieves. The authors thank the three anonymous reviewers for their valuable suggestions and comments.

\section{Author Contributions}

In this manuscript, Chen Du and Huazhong Ren provided the main ideas, developed the algorithm, evaluated the algorithm sensitivity and also wrote the whole manuscript. Both of them contributed equally. Qiming Qin evaluated the algorithm performance and helped much on processing Landsat 8 data. Jinjie Meng and Shaohua Zhao contributed to generate some graphs and revisions.

\section{Conflicts of Interest}

The authors declare no conflict of interest.

\section{References and Notes}

1. Price, J.C. The potential of remotely sensed thermal infrared data to infer surface soil-moisture and evaporation. Water Resour. Res. 1980, 16, 787-795.

2. Duan, S.-B.; Li, Z.-L.; Tang, B.-H.; Wu, H.; Tang, R.L.; Bi, Y.; Zhou, G. Estimation of diurnal cycle of land surface temperature at high temporal and spatial resolution from clear-sky MODIS data. Remote Sens. 2014, 6, 3247-3262. 
3. Duan, S.-B.; Li, Z.-L.; Tang, B.-H.; Wu, H.; Tang, R.L. Generation of a time-consistent land surface temperature product from MODIS data. Remote Sens. Environ. 2014, 140, 339-349.

4. Becker, F.; Li, Z.-L. Towards a local split window method over land surfaces. Int. J. Remote Sens. 1990, 11, 369-393.

5. Becker, F.; Li, Z.-L. Surface temperature and emissivity at various scales: Definition, measurement and related problems. Remote Sens. Rev. 1995, 12, 225-253.

6. Wan, Z.; Dozier, J. A generalized split-window algorithm for retrieving land-surface temperature from space. IEEE Trans. Geosci. Remote Sens. 1996, 34, 892-905.

7. Gillespie, A.; Rokugawa, S.; Matsunaga, T.; Cothern, J.S.; Hook, S.; Kahle, A.B. A temperature and emissivity separation algorithm for advanced spaceborne thermal emission and reflection radiometer (ASTER) images. IEEE Trans. Geosci. Remote Sens. 1998, 36, 1113-1126.

8. Becker, F.; Li, Z.-L. Temperature-independent spectral indexes in thermal infrared bands. Remote Sens. Environ. 1990, 32, 17-33.

9. Watson, K. Two-temperature method for measuring emissivity. Remote Sens. Environ. 1992, 42, 117-121.

10. Peres, L.F.; DaCamara, C.C. Land surface temperature and emissivity estimation based on the two-temperature method: Sensitivity analysis using simulated MSG/SEVIRI data. Remote Sens. Environ. 2004, 91, 377-389.

11. Wan, Z.; Li, Z.-L. A physics-based algorithm for retrieving land-surface emissivity and temperature from EOS/MODIS data. IEEE Trans. Geosci. Remote Sens. 1997, 35, 980-996.

12. Ingram, P.M.; Muse, A.H. Sensitivity of iterative spectrally smooth temperature/emissivity separation to algorithmic assumptions and measurement noise. IEEE Trans. Geosci. Remote Sens. 2001, 39, 2158-2167.

13. Kealy, P.S.; Hook, S.J. Separating temperature and emissivity in thermal infrared multispectral scanner data - implications for recovering land-surface temperatures. IEEE Trans. Geosci. Remote Sens. 1993, 31, 1155-1164.

14. Roy, D.P.; Wulder, M.A.; Loveland, T.R.; Woodcock, C.E.; Allen, R.G.; Anderson, M.C.; Helder, D.; Irons, J.R.; Johnson, D.M.; Kennedy, R.; et al. Landsat-8: Science and product vision for terrestrial global change research. Remote Sens. Environ. 2014, 145, 154-172.

15. Li, Z.-L.; Tang, B.-H.; Wu, H.; Ren, H.; Yan, G.; Wan, Z.; Trigo, I.F.; Sobrino, J.A. Satellite-derived land surface temperature: Current status and perspectives. Remote Sens. Environ. 2013, 131, 14-37.

16. Li, Z.-L.; Wu, H.; Wang, N.; Qiu, S.; Sobrino, J.A.; Wan, Z.; Tang, B.-H.; Yan, G. Land surface emissivity retrieval from satellite data. Int. J. Remote Sens. 2013, 34, 3084-3127.

17. Gao, C.; Li, Z.-L.; Qiu, S.; Tang, B.; Wu, H.; Jiang, X. An improved algorithm for retrieving land surface emissivity and temperature from MSG-2/SEVIRI data. IEEE Trans. Geosci. Remote Sens. 2014, 52, 3175-3191.

18. Li, Z.-L.; Petitcolin, F.; Zhang, R.H. A physically based algorithm for land surface emissivity retrieval from combined mid-infrared and thermal infrared data. Sci China Ser. E. 2000, 43, 23-33.

19. Wan, Z. New refinements and validation of the collection-6 MODIS land-surface temperature/emissivity product. Remote Sens. Environ. 2014, 140, 36-45. 
20. Chedin, A.; Scott, N.A.; Wahiche, C.; Moulinier, P. The improved initialization inversion method a high-resolution physical method for temperature retrievals from satellites of the Tiros-N Series. J. Climate Appl. Meteor. 1985, 24, 128-143.

21. Chevallier, F.; Chedin, A.; Cheruy, F.; Morcrette, J.J. TIGR-like atmospheric-profile databases for accurate radiative-flux computation. Quart. J. Roy. Meteorol. Soc. 2000, 126, 777-785.

22. Hulley, G.C.; Hook, S.J. The north American ASTER land surface emissivity database (NAASLED) version 2.0. Remote Sens. Environ. 2009, 113, 1967-1975.

23. Tang, B.-H.; Bi, Y.; Li, Z.-L.; Xia, J. Generalized split-window algorithm for estimate of land surface temperature from Chinese geostationary Fengyun meteorological satellite (FY-2C) data. Sensors 2008, 8, 933-951.

24. Snyder, W.C.; Wan, Z. BRDF models to predict spectral reflectance and emissivity in the thermal infrared. IEEE Trans. Geosci. Remote Sens. 1998, 36, 214-225.

25. Ren, H.; Yan, G.; Chen, L.; Li, Z.-L. Angular effect of MODIS emissivity products and its application to the split-window algorithm. ISPSR J. Photogramm. 2011, 66, 498-507.

26. Ren, H.; Liu, R.; Yan, G.; Mu, X.; Li, Z.-L.; Nerry, F.; Liu, Q. Angular normalization of land surface temperature and emissivity using multiangular middle and thermal infrared data. IEEE Trans. Geosci. Remote Sens. 2014, 52, 4913-4931.

27. Snyder, W.C.; Wan, Z.; Zhang, Y.; Feng, Y.Z. Classification-based emissivity for land surface temperature measurement from space. Int. J. Remote Sens. 1998, 19, 2753-2774.

28. Sun, D.; Pinker, R. Implementation of GEOS - based land surface temperature diurnal cycle to avhrr. Int. J. Remote Sens. 2005, 26, 3975-3984.

29. Trigo, I.F.; Peres, L.F.; DaCamara, C.C.; Freitas, S.C. Thermal land surface emissivity retrieved from SEVIRI/METEOSAT. IEEE Trans. Geosci. Remote Sens. 2008, 46, 307-315.

30. Gong, P.; Wang, J.; Yu, L.; Zhao, Y.; Zhao, Y.; Liang, L.; Niu, Z.; Huang, X.; Fu, H.; Liu, S.; et al. Finer resolution observation and monitoring of global land cover: First mapping results with Landsat TM and ETM+ data. Int. J. Remote Sens. 2013, 34, 2607-2654.

31. Belward, A.S.; Estes, J.E.; Kline, K.D. The IGBP-DIS global 1-km land-cover data set discover: A project overview. Photogramm. Eng. Remote Sens. 1999, 65, 1013-1020.

32. Loveland, T.R.; Reed, B.C.; Brown, J.F.; Ohlen, D.O.; Zhu, Z.; Yang, L.; Merchant, J.W. Development of a global land cover characteristics database and IGBP discover from $1 \mathrm{~km}$ AVHRR data. Int. J. Remote Sens. 2000, 21, 1303-1330.

33. Wan, Z.; Ng, D.; Dozier, J. Spectral emissivity measurements of land-surface materials and related radiative transfer simulations. Adv. Space Res. 1994, 14, 91-94.

34. Carlson, T.N.; Ripley, D.A. On the relation between NDVI, fractional vegetation cover, and leaf area index. Remote Sens. Environ. 1997, 62, 241-252.

35. Sobrino, J.A.; Raissouni, N.; Li, Z.-L. A comparative study of land surface emissivity retrieval from NOAA data. Remote Sens. Environ. 2001, 75, 256-266.

36. Sobrino, J.A.; Raissouni, N.; Simarro, J.; Nerry, F.; Petitcolin, F. Atmospheric water vapor content over land surfaces derived from the AVHRR data: Application to the Iberian Peninsula. IEEE Trans. Geosci. Remote Sens. 1999, 37, 1425-1434.

37. Li, Z.-L.; Jia, L.; Su, Z.; Wan, Z.; Zhang, R. A new approach for retrieving precipitable water from ATSR2 split-window channel data over land area. Int. J. Remote Sens. 2003, 24, 5095-5117. 
38. Schroedter-Homscheidt, M.; Drews, A.; Heise, S. Total water vapor column retrieval from MSG-SEVIRI split window measurements exploiting the daily cycle of land surface temperatures. Remote Sens. Environ. 2008, 112, 249-258.

39. Wang, N.; Li, Z.-L.; Tang, B.-H.; Zeng, F.N.A.; Li, C.R. Retrieval of atmospheric and land surface parameters from satellite-based thermal infrared hyperspectral data using a neural network technique. Int. J. Remote Sens. 2013, 34, 3485-3502.

40. Ren, H.; Du, C.; Qin, Q.; Liu, R.; Meng, J.; Li, J. Atmospheric water vapor retrieval from landsat 8 and its validation. In Proceedings of the IEEE International Geoscience and Remote Sensing Symposium (IGARSS), Quebec, QC, Canada, July 2014; pp. 3045-3048.

41. Irons, J.R.; Dwyer, J.L.; Barsi, J.A. The next landsat satellite: The landsat data continuity mission. Remote Sens. Environ. 2012, 122, 11-21.

42. Sobrino, J.A.; Li, Z.-L.; Stoll, M.P.; Becker, F. Improvements in the split-window technique for land-surface temperature determination. IEEE Trans. Geosci. Remote Sens. 1994, 32, 243-253.

43. Xiong, X.X.; Barnes, W. An overview of MODIS radiometric calibration and characterization. Adv. Atmos Sci. 2006, 23, 69-79.

44. Ren, H.; Du, C.; Liu, R.; Qin, Q.; Meng, J.; Li, Z.-L.; Yan, G. Evaluation of radiometric performance for the thermal infrared sensor onboard Landsat 8. Remote Sens. 2014, 6, $12776-12788$.

45. Jimenez-Munoz, J.C.; Sobrino, J.A.; Skokovic, D.; Mattar, C.; Cristobal, J. Land surface temperature retrieval methods from Landsat-8 thermal infrared sensor data. IEEE Geosci. Remote Sens. Lett. 2014, 11, 1840-1843.

46. Sobrino, J.A.; Li, Z.-L.; Stoll, M.P.; Becker, F. Multi-channel and multi-angle algorithms for estimating sea and land surface temperature with ATSR data. Int. J. Remote Sens. 1996, 17, 2089-2114.

47. Rozenstein, O.; Qin, Z.; Derimian, Y.; Karnieli, A. Derivation of land surface temperature for Landsat-8 TIRS using a split window algorithm. Sensors 2014, 14, 5768-5780.

48. Montanaro, M.; Lunsford, A.; Tesfaye, Z.; Wenny, B.; Reuter, D. Radiometric calibration methodology of the Landsat 8 thermal infrared sensor. Remote Sens. 2014, 6, 8803-8821.

49. Montanaro, M.; Gerace, A.; Lunsford, A.; Reuter, D. Stray light artifacts in imagery from the Landsat 8 thermal infrared sensor. Remote Sens. 2014, 6, 10435-10456.

(C) 2015 by the authors; licensee MDPI, Basel, Switzerland. This article is an open access article distributed under the terms and conditions of the Creative Commons Attribution license (http://creativecommons.org/licenses/by/4.0/). 